Check for updates

Cite this: RSC Adv., 2021, 11, 22625

\title{
Flexible hybrid photodetector based on silver sulfide nanoparticles and multi-walled carbon nanotubes $\dagger$
}

\author{
Sung Ho Kim, ${ }^{a}$ Jieun Lim, ${ }^{\text {ab }}$ Seonjeong Lee, ${ }^{a}$ Myung Hyun Kang, ${ }^{a}$ Wooseok Song, (D) \\ Jongsun Lim, (D) a Sunsuk Lee, (D) ${ }^{\text {a }}$ Eun Kyoung Kim, (iD ${ }^{\mathrm{b}}$ Joung Kyu Park (D) *a \\ and Sung Myung (D) *a
}

Herein, we reported a wearable photodetector based on hybrid nanocomposites, such as carbon materials and biocompatible semiconductor nanocrystals (NCs), exhibiting excellent photoresponsivity and superior durability. Currently, semiconductor nanocrystal quantum dots (QDs) containing heavy metals, such as lead or cadmium (in the form of lead sulfide (PbS) and cadmium sulfide (CdS)), are known to display excellent detection properties and are thus widely employed in the fabrication of photodetectors. However, the toxic properties of these heavy metals are well known. Hence, in spite of their enormous potential, the QDs based on these heavy metals are not generally preferred in biological or biomedical applications. These limitations, though, can be overcome by the judicious choice of alternate materials such as silver sulfide $\left(\mathrm{Ag}_{2} \mathrm{~S}\right) \mathrm{NCs}$, which are biocompatible and exhibit multiple excitons in $\mathrm{Ag}_{2} \mathrm{~S} \mathrm{QDs}$. The other chosen component is a carbon-based material, such as the multi-walled carbon nanotube (MWCNT), which is preferred primarily due to its strong and superior mechanical durability. In this study, a hybrid nanocomposite film was synthesized from $\mathrm{Ag}_{2} \mathrm{~S} N C s$ and MWCNTs by a simple one-step fabrication process using ultrasonic irradiation. Additionally, this method did not involve any chemical functionalization or post-processing step. The size of $\mathrm{Ag}_{2} \mathrm{~S} N C s$ in the hybrid film was controlled by the irradiation time and the power of the ultrasonic radiation. Further, appropriate composition ratio of the hybrid composite was optimized to balance the photo-response and mechanical durability of the photodetector. Thus, using this synthetic method, an excellent photoresponsivity property of the device was demonstrated for a near-infrared (NIR) light source with various light wavelengths. Furthermore, no visible change in photoresponsivity was observed for bending motions up to $10^{5}$ cycles and for a range of angles $\left(0-60^{\circ}\right)$. This novel method provides an eco-friendly alternative to existing functional composites containing toxic heavy metals and is a promising approach for the development of wearable optoelectronic devices.

rsc.li/rsc-advances

Received 30th April 2021

Accepted 22nd June 2021

DOI: 10.1039/d1ra03385a be applied to the human body require flexible and stable mechanical properties. A number of research groups have thus studied the hybridization of carbon materials (CNs) and semiconductor nanomaterials and their feasibility as complementary materials. CNs, such as carbon nanotubes (CNTs) or graphene, have been the focus of intense investigation owing to their excellent conductivity, flexibility, and durability. For example, hybrid nanostructures based on CNs have been utilized in optical devices that require ultrahigh responsivity because of the strong light absorption of $\mathrm{TiO}_{2}$ nanoparticles, $\mathrm{MoS}_{2}$, PZT, and other related organic compounds etc. ${ }^{3}$ Since the skin, consisting of the stratum corneum, epidermis, and dermis has an optical absorbance between 240 and $633 \mathrm{~nm}$, NIR radiation is preferred as it is capable of sending signals from deep inside the dermis owing to its substantial penetration depth into the skin. ${ }^{4}$ There have been many research reports on optical devices using QDs with excellent optical properties in
${ }^{a}$ Advanced Materials Division, Korea Research Institute of Chemical Technology,
Daejeon 34114, Korea. E-mail: parkjk@krict.re.kr; msung@krict.re.kr
${ }^{b}$ Department of Chemical and Biomolecular Engineering, Yonsei University, Seoul
03722, Korea
$\begin{array}{llll}\dagger \text { Electronic supplementary information } & \text { (ESI) available. See DOI: } \\ \text { 10.1039/d1ra03385a } & & \end{array}$ 
the NIR region; these are widely applied in the fabrication of patchable devices that could be attached to the human skin. ${ }^{5-8}$ QDs such as PbS, PbSe, and CdS with narrow band gaps or composites of QDs and CNs have been utilized to overcome the difficulty of applying semiconductor materials to NIR detectors, owing to their NIR detection characteristics. ${ }^{9-11}$ However, the hybrid materials employed in various optical and photonic devices contain heavy metals, such as lead and cadmium, which have toxic properties and therefore are fatal to the human body. This aspect has proven to be a critical limitation in their application to wearable devices. To overcome this issue, biocompatible $\mathrm{Ag}_{2} \mathrm{~S}$ nanoparticles ( $\mathrm{Ag}_{2} \mathrm{~S}$ NPs) have been extensively studied for application in optoelectronic devices such as photocells and photoconductors owing to their high biocompatibility and unique absorption ability in the UV-NIR region. ${ }^{12,13}$ Highly flexible and mechanically stretchable properties should be required for wearable optoelectronic devices. However, despite the ductile properties of $\mathrm{Ag}_{2} \mathrm{~S}$ film, the thin layer based on only $\mathrm{Ag}_{2} \mathrm{~S}$ NPs was fractured easily under bending conditions due to the poor interface adhesion. ${ }^{\mathbf{1 4}}$ To solve this issue, we synthesized $\mathrm{Ag}_{2} \mathrm{~S}$ on CNTs with excellent mechanical stability and electrical conductivity, and prepared hybrid layers consisted of $\mathrm{Ag}_{2} \mathrm{~S}$ NPs and CNTs.

In this work, we demonstrate efficient NIR photodetectors with hybrid nanocomposite films based on $\mathrm{Ag}_{2} \mathrm{~S}$ NPs and CNTs. Nanocomposites based on CNTs and $\mathrm{Ag}_{2} \mathrm{~S}$ NPs (CNT-ANs) were successfully synthesized by a simple one-step solution process using ultrasonic irradiation. The sonochemical method is an effective technique for the synthesis of nanomaterials with unique shapes and properties. Moreover, this technique has a strong enough propagation pressure to create bubble formation and to hold an incomplete collapse in the solution. ${ }^{15}$ The optimized synthesis of CNT-ANs was determined by adjusting the $\mathrm{Ag}_{2} \mathrm{~S}$ proportion in CNT-ANs, and the NIR detectors based on CNT-ANs were characterized against light exposure at different wavelengths and photo power densities.

Our NIR detector based on CNT-ANs exhibits an excellent photo-response of $278.22 \mathrm{~A} \mathrm{~W}^{-1}$ under light exposure (wavelength of $800 \mathrm{~nm}$ ) with a power density of $0.15 \mathrm{~mW} \mathrm{~cm}^{-2}$, which is considerably higher than that of photodetectors based on CNT-PbS. ${ }^{16}$ In addition, this synthetic method based on CNTANs allowed us to improve the physical flexibility and sensitivity of the photodetector; moreover, these materials exhibit excellent properties. These synthesis methods and optoelectronic properties suggest a facile and an efficient approach for fabricating hybrid optoelectronic devices for various applications, including flexible devices and advanced wearable sensors. Furthermore, it could prove to be a viable replacement to previous devices based on heavy metal materials.

\section{Experimental}

Synthesis of CNT-ANs based multi-walled CNTs and $\mathrm{Ag}_{2} \mathrm{~S}$ NPs

$\mathrm{Ag}_{2} \mathrm{~S}$ NPs and CNT-ANs were prepared using a sonochemical method. For the synthesis of $\mathrm{Ag}_{2} \mathrm{~S}$ NPs, $1 \mathrm{mmol}$ of $\mathrm{AgNO}_{3}$ was added to $10 \mathrm{~mL}$ of 1-dodecanethiol (DDT). The solution was treated by ultrasound radiation for $30 \mathrm{~min}$, and the resulting suspension was centrifuged several times using ethyl acetate to remove any residual by-products. The obtained $\mathrm{Ag}_{2} \mathrm{~S}$ NPs were dispersed in isopropyl alcohol $\left(1 \mathrm{mg} \mathrm{mL}^{-1}\right)$. The CNT-ANs too were synthesized in a similar way, wherein, $\mathrm{AgNO}_{3}$ and multiwalled CNTs were added to the DDT solution. During the synthetic procedure, the concentrations of CNTs and DDT were kept constant while the concentration of $\mathrm{AgNO}_{3}$ was varied from 0.1 to $2 \mathrm{mM}$.

\section{Fabrication of photodetector based on CNT-ANs}

A schematic of the CNT-AN-based photodetector fabrication process is shown in Fig. 1(a). Fig. 1(a-i) reveal the synthesis of CNT-ANs by the sonochemistry method using the mixture of $\mathrm{CNT}, \mathrm{AgNO}_{3}$, and DDT. In this work, the amounts of CNT and DDT were kept constant, while the concentration of $\mathrm{AgNO}_{3}$ was adjusted to various proportions $(1: 1,1: 5,1: 10$, and $1: 20)$ of CNT-ANs. As a result, CNT-ANs were successfully synthesized and dispersed in a highly volatile alcohol-based isopropyl alcohol solvent. Additionally, $\mathrm{Ag}_{2} \mathrm{~S}$ NPs, when dispersed in various organic solvents, were observed to remain intact without precipitation even after three months (Fig. S1 in ESI $\dagger$ ) because of the presence of DDT as a protective coat on the surface of NPs. ${ }^{17}$ The CNT-ANs were then spray-coated on to $\mathrm{SiO}_{2}$ or polydimethylsiloxane (PDMS) substrates for the fabrication of the CNT-ANs film. Subsequently, it was annealed in a vacuum oven to remove residual solvents present within (Fig. 1 (a-ii)). In the final step, a metallic source-drain electrode was formed by thermal evaporation on top of the CNT-ANs film, as shown in Fig. 1 (a-iii).

\section{Results and discussion}

The surface morphology of CNT-ANs was first investigated using field emission scanning electron microscopy (FE-SEM) (Fig. 1(b)), wherein the ratio of CNTs to $\mathrm{Ag}_{2} \mathrm{~S}$ NPs was varied from $1: 1$ to $1: 20 . \mathrm{Ag}_{2} \mathrm{~S}$ NPs were found to have grown on the CNT surface, and the size of $\mathrm{Ag}_{2} \mathrm{~S}$ NPs was observed to increase with a corresponding increase in the proportion of $\mathrm{AgNO}_{3}$ added. Thus, large $\mathrm{Ag}_{2} \mathrm{~S}$ NPs were observed when using small capping ligands, such as DDT, at relatively high reaction temperatures. Also, transmission electron microscope (TEM) investigation confirmed that the particle size of $\mathrm{Ag}_{2} \mathrm{~S}$ NPs is approximately $10 \mathrm{~nm}$ (Fig. S2 in ESI $\dagger$ ), and scanning electron microscopy with energy dispersive X-ray spectroscopy (SEMEDS) shows the existence of C, Ag and S elements in CNT-ANs (Fig. S3 in ESI $\dagger$ ). In addition, it was observed that the density of excess $\mathrm{Ag}_{2} \mathrm{~S}$ NPs increased on the CNT surfaces during the synthesis of NPs, resulting in high proportions of $\mathrm{Ag}_{2} \mathrm{~S}$ NPs. ${ }^{18}$ However, cracks in the CNT-AN films by excess $\mathrm{Ag}_{2} \mathrm{~S}$ NPs resulted in a decrease in the electrical conductivity between grains (Fig. S4 in ESI $\dagger$ ). ${ }^{19}$ Additionally, $\mathrm{Ag}_{2} \mathrm{~S}$ NPs in CNT-ANs have poor crystallinity when using a low-power sonication radiation. Hence, NPs were synthesized successfully under a sonication radiation of high power for over $120 \mathrm{~min}$ (Fig. S5 in ESI $\dagger$ ). ${ }^{20}$ The structural characterization of the various synthesized CNT-ANs (Fig. 1(c)) was performed using X-ray diffraction (XRD). A number of Bragg diffraction peaks of $\alpha$-phase $\mathrm{Ag}_{2} \mathrm{~S}$ NPs 
a) (i)

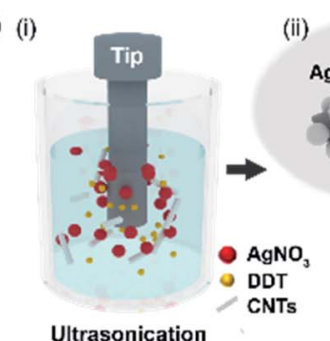

(ii)

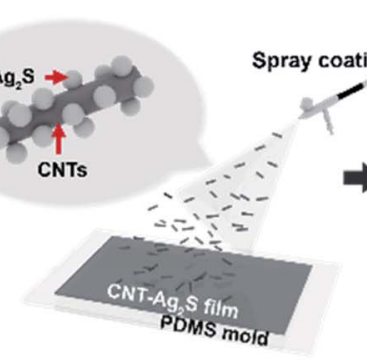

(iii)
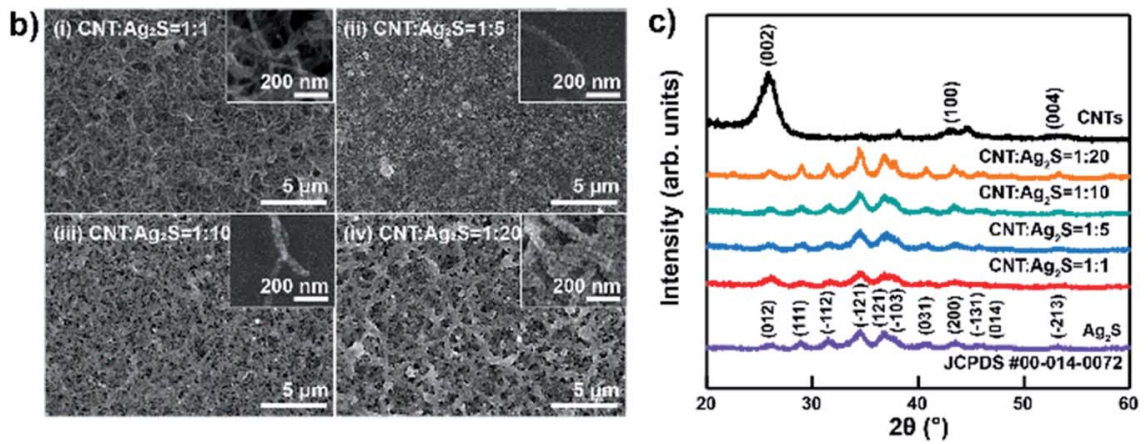

Fig. 1 (a) Schematic of the fabrication of photodetectors based on CNT-ANs: (i) synthesis of the CNT-ANs based on multi-walled CNTs, AgNO3, and DDT by ultrasonic irradiation, (ii) hybrid structure of CNT-ANs and deposition of the CNT-ANs film on PDMS substrate by spray-coating method, (iii) fabrication of the electrodes on the CNT-ANs film for photodetector. (b) (i-iv) SEM images of CNT-ANs synthesized in various proportions. Here, the scale bar is $5 \mu \mathrm{m}$, and the inset shows the magnified SEM image of deposited CNT-ANs for various solution concentrations (scale bar is $200 \mathrm{~nm}$ ). (c) XRD patterns of the CNT-ANs in various proportions.

were observed at $2 \theta$ values of $26.323^{\circ}, 28.966^{\circ}, 31.521^{\circ}, 36.557^{\circ}$, $36.806^{\circ}, 37.719^{\circ}, 43.407^{\circ}$, and $45.426^{\circ}$, which could be successfully indexed as (012), (111), (-112), (-121), (121), (-103), (200), and (-131) diffraction planes $\left(\mathrm{Ag}_{2} \mathrm{~S}\right.$, \#JCPDF 00014-0072), respectively. ${ }^{21,22}$ In the XRD pattern of CNTs, the observed peaks at $25.919,42.959$, and $53.29^{\circ}$ were assigned to (002), (100), and (004) diffraction planes (CNTs, \#JCPDF 00-0581638), respectively. Moreover, the XRD peak intensity of CNTANs increased with an increase in NP precursors indicating that the crystallinity of $\mathrm{Ag}_{2} \mathrm{~S}$ was improved. Further, the observed XRD pattern of CNT-ANs was quite similar to that of the $\mathrm{Ag}_{2} \mathrm{~S}$ NPs, suggesting that the internal phase structure of $\mathrm{Ag}_{2} \mathrm{~S}$ does not undergo any significant change when combined with CNT. In particular, no characteristic (002) diffraction peaks of CNTs were observed in the XRD pattern of the hybrid nanocomposite CNT-ANs. The primary reason for this trend is the presence of low amounts of CNTs as large amounts of $\mathrm{Ag}_{2} \mathrm{~S}$ are present on the surface. Moreover, as the ratio of $\mathrm{Ag}_{2} \mathrm{~S}$ increased, the full width at half maximum (FWHM) value of the $(-112)$ peak decreased, indicating that the particle size increased gradually. ${ }^{23}$

The surface chemical composition analysis of different proportions of CNT-AN samples was investigated via X-ray photoelectron spectroscopy (XPS) (Fig. 2(a)). The Ag 3d core level spectrum for the $\mathrm{Ag} 3 \mathrm{~d}_{5 / 2}$ and $\mathrm{Ag} 3 \mathrm{~d}_{3 / 2}$ peaks showed a strong intensity and a set of symmetric peaks at 368.08 and $374.28 \mathrm{eV}$, respectively. There were no shoulder or satellite peaks observed between the $\mathrm{Ag} 3 \mathrm{~d}$ peaks. Further, the intensity of the peak too was observed to increase with an increase in the concentration of $\mathrm{Ag}_{2} \mathrm{~S}$. In the $\mathrm{S} 2 \mathrm{p}$ core-level spectrum, the $\mathrm{S} 2 \mathrm{p}_{1 / 2}$ and $\mathrm{S} 2 \mathrm{p}_{3 / 2}$ peaks were observed at 162.58 and $161.48 \mathrm{eV}$, respectively. ${ }^{24}$ The intensity of the silver peak was observed to increase gradually with the respective atomic ratios ranging between $1: 1.33$ and $1: 2$ (Fig. S6 in ESI†). All the obtained XPS profiles were calibrated against the $\mathrm{C} 1 \mathrm{~s}$ peak located at $284.48 \mathrm{eV}$. The peak at $284.7 \mathrm{eV}$ was assigned to the $\mathrm{sp}^{2}$ hybridized carbon (C-C), and the peak at $285.5 \mathrm{eV}$ was assigned to the $\mathrm{C}-\mathrm{S}$ bonding peak according to sulfur. When the survey peak in CNT-ANs was measured with various proportions of $\mathrm{Ag}_{2} \mathrm{~S}$, the intensity of the carbon peak decreased gradually with a proportional increase in the amount of $\mathrm{Ag}_{2} \mathrm{~S}$. In addition, as the ratio of $\mathrm{Ag}_{2} \mathrm{~S}$ in the CNTANs sample increased, the intensity of the C-S bonding peak too was observed to become stronger. To compare the characteristics of CNT-ANs, three different samples of thin films were prepared based on CNT-ANs, mixtures of DDT with CNTs, and CNTs using the same synthetic method (Fig. S7 in ESI $\dagger$ ). When DDT was added to the CNT solution, sulfur peaks associated with the DDT solution were observed. In addition, the mixture of DDT and CNT exhibited a low intensity for $\mathrm{C}-\mathrm{O}$ and $\mathrm{COOH}$ bonding and a high intensity for the $\mathrm{C}-\mathrm{S}$ bonding. On the other hand, when $\mathrm{AgNO}_{3}$ was added to the CNT-DDT solution mixture, sulfur peaks related to $\mathrm{Ag}_{2} \mathrm{~S}$ in the thin film were observed. Moreover, a higher intensity of C-S bonding in $\mathrm{C} 1 \mathrm{~s}$ was obtained this time when compared to its intensity values in the CNT-DDT only mixture (i.e. the mixture without $\mathrm{AgNO}_{3}$ ). This indicates that sulfur is formed first on the CNTs and $\mathrm{AgNO}_{3}$ reacts sequentially to form $\mathrm{Ag}_{2} \mathrm{~S}$ NPs. Fourier transform-infrared (FT-IR) spectroscopy was used to investigate the surface modification of CNTs by DDT and $\mathrm{AgNO}_{3}{ }^{25}$ The results are shown in Fig. S8 in ESI. $\dagger$ For CNTs, the spectra exhibited almost no functional groups on the surface. However, after synthesis, the 

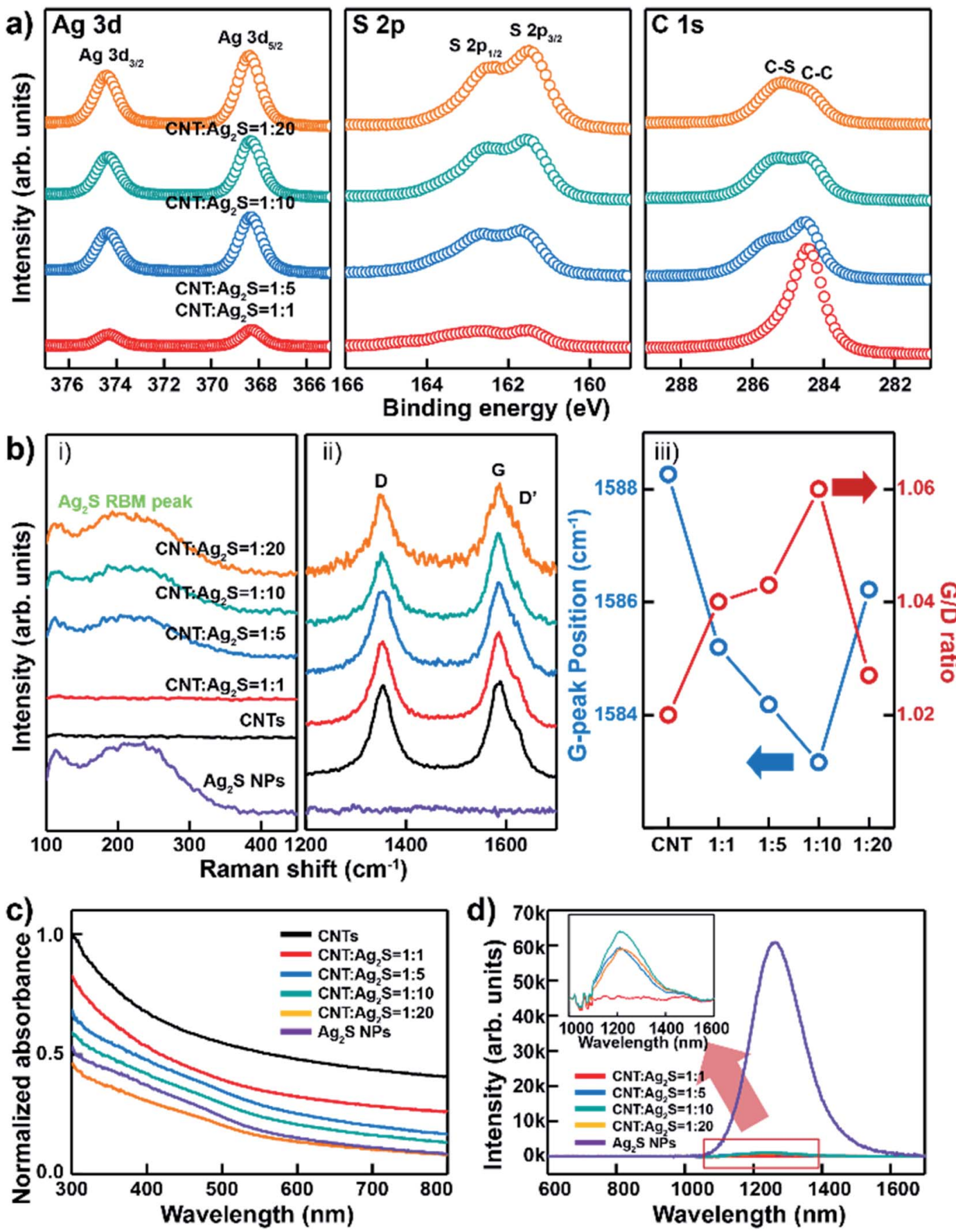

Fig. 2 Characterization of CNT-ANs synthesized in various proportions (1:1,1:5,1:10,1:20 (CNT: Ag 2 S)). (a) XPS profiles of the Ag 3d, S 2p, and $C$ 1s core levels of the CNT-ANs. (b) Raman spectra of CNT-ANs under the $514 \mathrm{~nm}$ laser excitation. (i) RBM peaks of $A g_{2} S$, (ii) D, $D^{\prime}$, and G peak positions, (iii) G/D ratio and G peak positions. (c) Absorption spectra of CNT-ANs (d) PL emission spectra of the CNT-ANs at an excitation wavelength of $460 \mathrm{~nm}$.

CNTs revealed the presence of various kinds of functional groups. The bands at 2917 and $2848 \mathrm{~cm}^{-1}$ correspond to the $\mathrm{C}-\mathrm{H}$ stretching vibrations. This indicates that the $\mathrm{Ag}_{2} \mathrm{~S}$ NPs are bound to CNTs by a variety of functional groups.

As shown in the Raman spectra of CNTs, $\mathrm{Ag}_{2} \mathrm{~S}$ NPs, and CNTANs (Fig. 2(b)-(i and ii)), the D-band, G-band, and D'-band peaks were measured according to the radial breathing mode (RBM) of $\mathrm{Ag}_{2} \mathrm{~S}^{26}$ In this case, the Raman spectra were recorded at an excitation wavelength of $514 \mathrm{~nm}$. As the peaks at $1437 \mathrm{~cm}^{-1}$ arise from the vibrations of silver metal and sulfur oxide compounds, which are formed due to the photo-induced decomposition of $\mathrm{Ag}_{2} \mathrm{~S}$ in air under the exposure of high laser excitation power (Fig. S9 in ESI $\dagger$ ), the measurement was performed at a relatively low power (power $<0.86 \mathrm{~mW}$ ) of the laser radiation. ${ }^{27}$ The $\mathrm{RBM}$ peak in the Raman spectrum originated from the phonon vibration mode of $\mathrm{Ag}-\mathrm{S}$ bonding in $\mathrm{Ag}_{2} \mathrm{~S}$ NPs. 

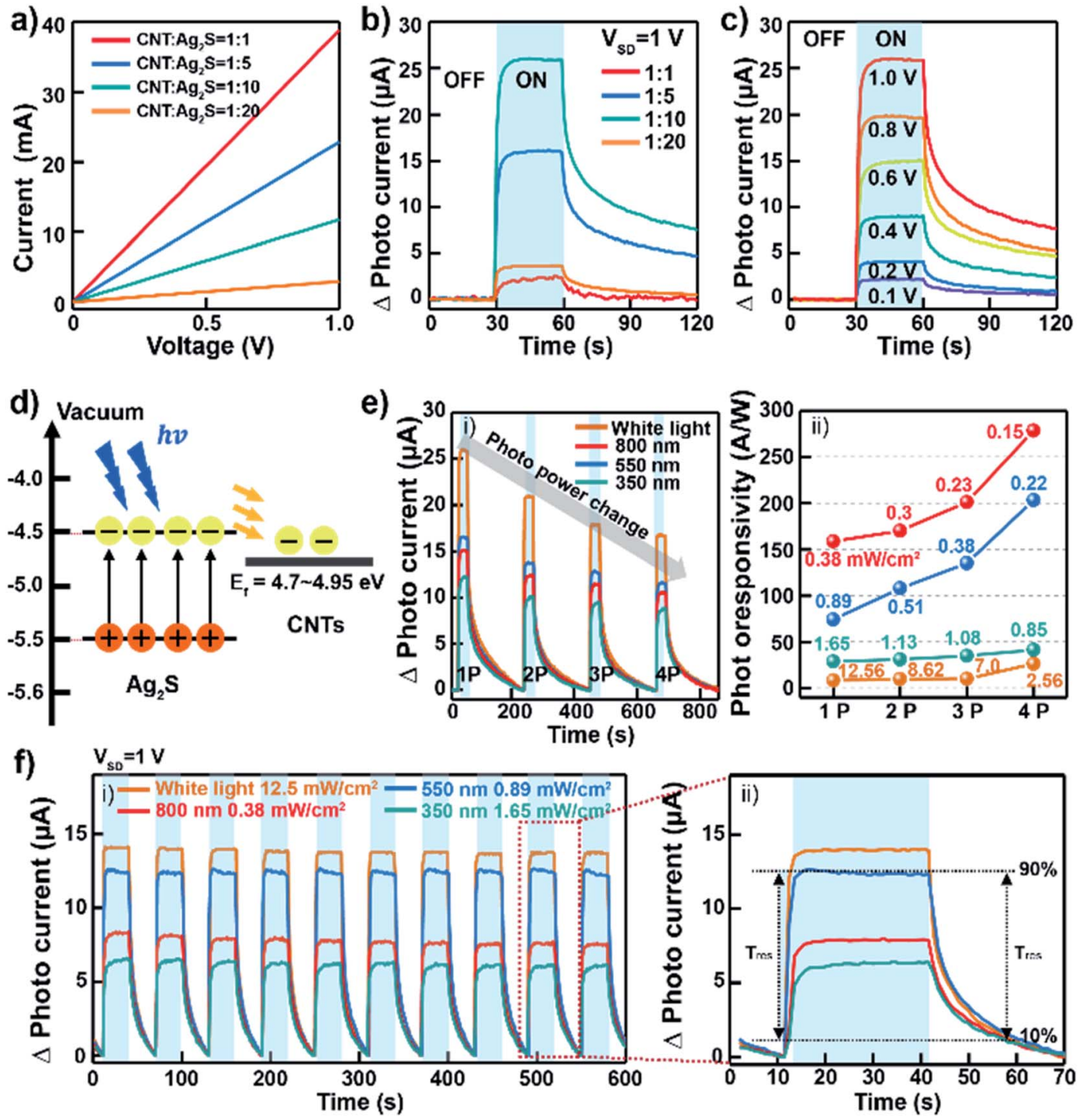

Fig. 3 Optoelectrical properties of CNT-AN-based films on $\mathrm{SiO}_{2}$ substrates. (a) Current-voltage (I-V) characteristic curves of the CNT-ANbased films. (b) Photocurrent of photodetector based on CNT-ANs under white light exposure. (c) photocurrent of photo devices based on CNT-ANs with a $1: 10$ (CNT : $\mathrm{Ag}_{2} \mathrm{~S}$ ) proportion as a function of the source-drain bias voltage. (d) Schematic energy band diagram of the Fermi levels of CNT and $\mathrm{Ag}_{2} \mathrm{~S}$ NPs. (e) Photo responsivity of the photodetector based on CNT-ANs with a $1: 10$ (CNT: Ag 2 S) proportion. (i and ii) Photocurrent due to the exposure to various light sources such as white light, and light at 800, 550, and $350 \mathrm{~nm}$ wavelength. The source-drain bias voltage $\left(V_{S D}\right)$ is $1 \mathrm{~V}$. ( $f$ ) (i) Photo-response of devices based on CNT-ANs with a $1: 10\left(C N T\right.$ : $\left.\mathrm{Ag}_{2} \mathrm{~S}\right)$ proportion under cyclic illumination with white-light, 800,550 , and $350 \mathrm{~nm}$ for a corresponding power density of $12.5,0.38,0.89$, and $1.65 \mathrm{~mW} \mathrm{~cm}^{-2}$, and (ii) the response times $\left(\tau_{\text {res }}\right)$ and decay time $\left(\tau_{\text {dec }}\right)$ under white light illumination.

Broad peaks at $250 \mathrm{~cm}^{-1}$ were observed for $\mathrm{Ag}_{2} \mathrm{~S}$ NPs, but not for CNTs. It is worth noting that $\mathrm{Ag}_{2} \mathrm{~S}$ NPs were well formed on the CNT surface. However, in the case of the $1: 1$ (CNT: $\mathrm{Ag}_{2} \mathrm{~S}$ ) proportion, the RBM peak was not obtained because $\mathrm{Ag}_{2} \mathrm{~S}$ NPs were not synthesized yet, which can be seen from the XPS results presented in Fig. 2(a). It seems that the amount of $\mathrm{Ag}_{2} \mathrm{~S}$ was too small for the complete synthesis of the NPs. Additionally, with an increase in the proportion of $\mathrm{Ag}_{2} \mathrm{~S}$, a blue-shift of the G-band and an increase in the intensity ratio of the D and $G$ bands $\left(I_{\mathrm{D}} / I_{\mathrm{G}}\right)$ were observed (Fig. 2(b-iii)). This could be attributed to the increasing density of $\mathrm{Ag}_{2} \mathrm{~S}$ on the CNT surface and the net n-type doping effect of $\mathrm{Ag}_{2} \mathrm{~S}$ NPs on CNTs. ${ }^{28}$ In the case of the mixture with a $1: 20\left(\mathrm{CNT}: \mathrm{Ag}_{2} \mathrm{~S}\right)$ ratio, the defect concentration increased and a reverse shift from non-bonding $\mathrm{Ag}_{2} \mathrm{~S}$ NPs was observed.

Fig. 2(c) shows the absorption spectra of CNTs, $\mathrm{Ag}_{2} \mathrm{~S}$, and CNT-ANs. No characteristic absorption peak was observed for CNTs, while a peak of absorption in the 400-500 $\mathrm{nm}$ range was recorded for $\mathrm{Ag}_{2} \mathrm{~S}$ NPs and CNT-ANs. ${ }^{29}$ The charge transfer between $\mathrm{Ag}_{2} \mathrm{~S}$ NPs and CNT-ANs was investigated by photoluminescence (PL) analysis (Fig. 2(d)). $\mathrm{Ag}_{2} \mathrm{~S}$ NPS show a PL emission band at approximately $1264.89 \mathrm{~nm}$, while the CNT-AN films show a relatively low peak intensity than $\mathrm{Ag}_{2} \mathrm{~S}$. PL emission quenching of $\mathrm{Ag}_{2} \mathrm{~S}$ NPs in CNT-ANs resulted due to the 
a)

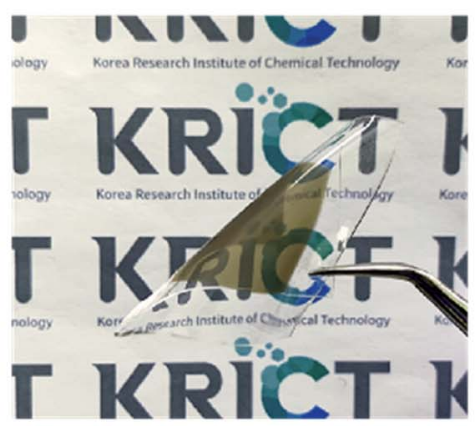

c)

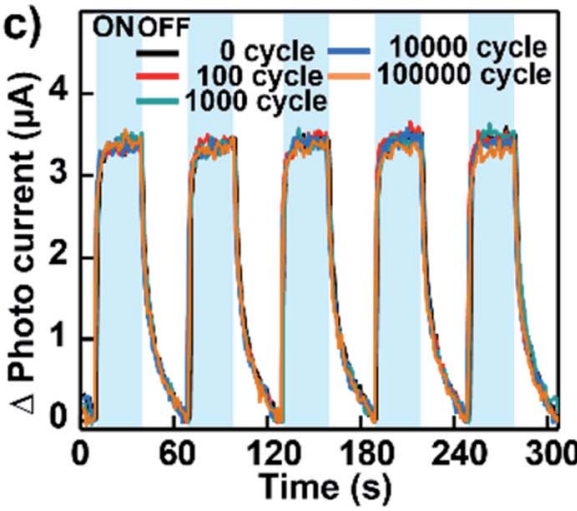

b)
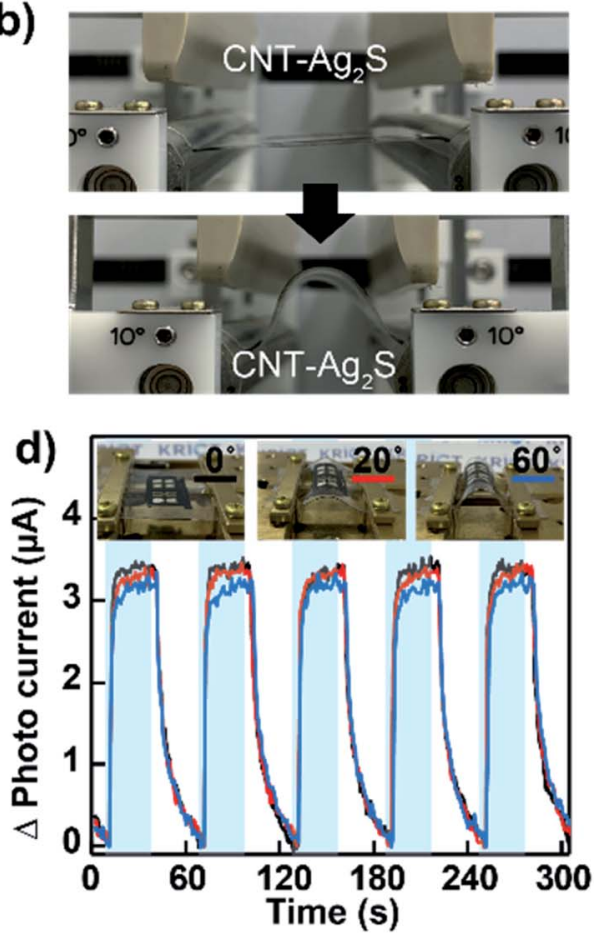

Fig. 4 Flexibility and durability performances of films based on CNT-ANs with a $1: 10$ (CNT : $\mathrm{Ag}_{2} \mathrm{~S}$ ) proportion. (a) Photograph of CNT-ANs film on a PDMS mold substrate. (b) Bending test of CNT-ANs films. (c) Photo-response according to the number of bending cycles (bending radius $=$ $5 \mathrm{~mm}$ ). (d) Photo-response after bending at wide angles $\left(0^{\circ}-60^{\circ}\right)$. The insets show bending test of CNT-ANs.

charge transfer from photo-excited $\mathrm{Ag}_{2} \mathrm{~S}$ NPs to $\mathrm{CNTs}^{30}$ In addition, a remarkable blue-shift of the emission peak was observed at $1210.25 \mathrm{~nm}$ for all the films with mixture ratios of $1: 5,1: 10$, and $1: 20\left(\mathrm{CNT}: \mathrm{Ag}_{2} \mathrm{~S}\right)$ except for the film with the proportion ratio of $1: 1\left(\mathrm{CNT}: \mathrm{Ag}_{2} \mathrm{~S}\right)$, which did not exhibit any PL peak. This blue-shift is explained by the change in the initial electronic density and confinement energy of the $\mathrm{Ag}_{2} \mathrm{~S} \mathrm{NPs}^{31,32}$

Thin film layers based on CNT-ANs for flexible photodetectors were fabricated by spray-coating on an ultraviolet lighttreated $\mathrm{SiO}_{2}$ substrate. Here, the thickness of the CNT-ANs was about $480 \mathrm{~nm}$ (Fig. S10 in ESI†). Source/drain electrodes ( $5 \mathrm{~nm} \mathrm{Cr} /$ $70 \mathrm{~nm} \mathrm{Au}$ ) were deposited on the CNT-ANs film through a shadow mask. The channel length and width of the device were 50 and 500 $\mu \mathrm{m}$, respectively. The current-voltage $(I-V)$ curve shows the conductivity of each synthesized CNT-ANs film within $1 \mathrm{~V}$ (Fig. 3(a)). The curve shows a clear linear response wherein the current of the CNT-ANs film was observed to increase with a corresponding decrease in $\mathrm{Ag}_{2} \mathrm{~S}$ proportions. Fig. 3(b) shows the photocurrent of the fabricated photodetectors based on CNT-ANs under white light exposure. The CNT-ANs device with a $1: 10$ (CNT : $\mathrm{Ag}_{2} \mathrm{~S}$ ) proportion exhibits the best on-state photocurrent with the recorded value being $26.03 \mu \mathrm{A}$. Photoresponsivity $(R)$ of the $1: 10 \mathrm{CNT}-\mathrm{Ag}_{2} \mathrm{~S}$ photodetector with the best photocurrent was calculated by using $R=\left(I_{\text {Photo }}-I_{\text {Dark }}\right) / P S$, where $P$ is light intensity, $S$ is the illuminated area of the channel. $R$ of our device is $8.3 \mathrm{~A}$ $\mathrm{W}^{-1}$ under white light exposure. In addition, the photosensitivity and detectivity were $5.7 \times 10^{4}$ and $1.7 \times 10^{10}$ Jones, respectively. The value of the gain $(G)$ coefficient at wavelengths of 350,550 , $800 \mathrm{~nm}$ were $29.52,18.78,12.91$, respectively. It is notable that as the wavelength of incident light increases, the gain of photodetectors decreases. Fig. 3(c) exhibits the typical photoresponsivity of CNT-ANs (with a $1: 10\left(\mathrm{CNT}: \mathrm{Ag}_{2} \mathrm{~S}\right)$ proportion) as a function of the source-drain voltage under light exposure with a power density of $12.26 \mathrm{~mW} \mathrm{~cm}{ }^{-2}$. The observed change of photocurrent with increasing source-drain voltage leads to an increase in the current of the photodetector. The trend continued until the maximum current was reached at a source-drain voltage of $1 \mathrm{~V}$. Fig. S11 in ESI $\dagger$ show the photocurrent in logarithmic scale according to drain voltage. Fig. 3(d) shows a schematic of the energy band alignment with the photodetection mechanism. In the case of nanoscale NPs, the band gap broadening phenomenon can occur because of the strong internal forces to the lattice of the nanoscale materials. Also, Akamatsu et al. showed that the band gap of $\mathrm{Ag}_{2} \mathrm{~S}$ NPs larger than $5 \mathrm{~nm}$ almost equal to that of the $\mathrm{Ag}_{2} \mathrm{~S}$ bulk value. ${ }^{33}$ As mentioned before, the diameter of $\mathrm{Ag}_{2} \mathrm{~S} \mathrm{NP}$ in this study was $10 \mathrm{~nm}$, which indicates that there is no quantum confinement effect on NPs and the band gap $\left(E_{\mathrm{g}}\right)$ of our $\mathrm{Ag}_{2} \mathrm{~S}$ NP is around $1 \mathrm{eV}^{34,35}$ The conduction band minimum (CBM) and valence band maximum (VBM) of $\mathrm{Ag}_{2} \mathrm{~S}$ NPs are taken to be 4.5 and $5.4 \mathrm{eV}$, respectively ${ }^{36}$ The work function of CNTs is in the range of 4.7$4.95{ }^{37,38}$ When the device is exposed to light, photoexcited electrons are transferred from the $\mathrm{Ag}_{2} \mathrm{~S}$ NPs to the CNTs owing to the efficient electron conductivity of the CNTs, which leads to a decrease in the PL intensity. ${ }^{30,31}$

We obtained the power dependence of the photocurrent of photodetectors based on CNT-ANs with a $1: 10\left(\mathrm{CNT}: \mathrm{Ag}_{2} \mathrm{~S}\right)$ at a source-drain voltage of $1 \mathrm{~V}$ under illumination with white light, with light having wavelengths of 800,550 , and $350 \mathrm{~nm}$ 
(Fig. 3(e)-(i and ii)), respectively. The obtained results indicated that the photocurrent changed continuously with the photopower density, with the best recorded photo-responsivity being $278.22 \mathrm{~A} \mathrm{~W}^{-1}$ at a wavelength of $800 \mathrm{~nm}(0.15 \mathrm{~mW}$ $\mathrm{cm}^{-2}$ ) of the NIR light source. This response, displaying an excellent reactivity in the NIR wavelength range, is notably higher than that of the PbS/CNT-based photodetectors reported in previous studies. ${ }^{16,39}$ This could be ascribed to the excellent absorption characterization of $\mathrm{Ag}_{2} \mathrm{~S}$ NPs in the NIR region. ${ }^{\mathbf{4 0 , 4 1}}$

In this study, CNT-ANs that do not contain heavy metals such as $\mathrm{Pb}$ or $\mathrm{Cd}$, were successfully synthesized and applied in the fabrication of flexible and implantable NIR photodetectors. Fig. 3(f)-(i) shows the photo-response of devices based on CNTANs with a $1: 10\left(\mathrm{CNT}: \mathrm{Ag}_{2} \mathrm{~S}\right)$ proportion under cyclic illumination with white light and at wavelengths 800,550 , and $350 \mathrm{~nm}$ for corresponding power densities of $12.5,0.38,0.89$, and 1.65 $\mathrm{mW} \mathrm{cm}^{-2}$. The recorded photocurrents were observed to be constant for up to $600 \mathrm{~s}$, further confirming the superior performance and stability of the devices. Fig. 3(f)-(ii) shows the response time $\left(\tau_{\text {res }}\right)$ and decay time $\left(\tau_{\text {dec }}\right)$ under white-light illumination. The measured $\tau_{\text {res }}$, for which the photocurrent rises from 10 to $90 \%$ of maximum, was $1.18 \mathrm{~s}$, while the measured $\tau_{\text {dec }}$ was $15.16 \mathrm{~s}$. Additionally, in cases where the illumination wavelengths were below 800, 550, and $350 \mathrm{~nm}$, the response speed was observed to decrease slightly (Table S1 in ESI $\dagger$ ).

To verify the applicability of wearable devices to human skin and the durability of our CNT-AN films for flexible photodetectors, flexible devices based on CNT-ANs were fabricated on a PDMS substrate by spray-coating. The sensing performance was measured according to the bending cycles and bending angles (Fig. 4(a)). In this work, a bending tester (JUNIL TECH Co., LTD-JIBT-610-Radius Bending) was used with a bending radius of $5 \mathrm{~mm}$ (Fig. 4(b)). Although the photo-response was relatively reduced because of the quenching effect of the substrate, the photodetection performance remained stable even after $10^{5}$ bending cycles (Fig. 4(c)). Moreover, the photocurrent maintains almost the same response at high bending angles $\left(0-60^{\circ}\right)$ (Fig. 4(d))..$^{42}$ This result demonstrates the good mechanical stability of the devices owing to the superior mechanical flexibility characteristic of CNTs. This approach, thus, may pave the way forward for the fabrication of advanced flexible photoelectronic devices.

\section{Conclusions}

In summary, lead-free hybrid structures based on CNTs and biocompatible $\mathrm{Ag}_{2} \mathrm{~S}$ NPs were successfully synthesized by ultrasonication to produce high-performance flexible photodetectors. The synthesized CNT-ANs exhibited high responsivity and excellent sensitivity under various illumination wavelengths. In particular, NIR detectors based on CNT-ANs exhibited an excellent photo-response of $278.22 \mathrm{~A} \mathrm{~W}^{-1}$ under a light exposure with a power density of $0.15 \mathrm{~mW} \mathrm{~cm} \mathrm{~cm}^{-2}$ and $800 \mathrm{~nm}$ wavelength, showing the possibility of its application as an NIR detector. In addition, flexible photodetectors based on CNT-ANs were mechanically and electrically stable after $10^{5}$ bending cycles and high bending angles. We believe that our synthesis methods and their optoelectronic properties present a facile and efficient approach for manufacturing wearable optoelectronic devices.

\section{Author contributions}

S. K, J. L., S. L., M.K. and W. S. contributed to the fabrication of photodetectors with hybrid nanocomposite films based on $\mathrm{Ag}_{2} \mathrm{~S}$ NPs and CNTs. J. L., S. L., S. S. L., and J. P. performed experimental measurements and analysed the data. S. K and S. M. conceived and designed the experiments, and S. K., S. L. and S. M. wrote the manuscript, and all authors discussed the results and commented on the manuscript.

\section{Conflicts of interest}

There are no conflicts to declare.

\section{Acknowledgements}

This research was supported by the Nano/Material Technology Development Program through the National Research Foundation of Korea (NRF) funded by the Ministry of Education, Science and Technology (NRF-2017M3D9A1073502). This research was also supported by the Bio \& Medical Technology Development Program of the National Research Foundation (NRF) funded by the Ministry of Science, ICT \& Future Planning (NRF-2020M3A9E4039224).

\section{References}

1 J. An, T. D. Le, C. H. J. Lim, V. T. Tran, Z. Zhan, Y. Gao, L. Zheng, G. Sun and Y. J. Kim, Adv. Sci., 2018, 5, 1800496.

2 Y. Liu, M. Pharr and G. A. Salvatore, ACS Nano, 2017, 11, 9614-9635.

3 X. Chen, K. Shehzad, L. Gao, M. Long, H. Guo, S. Qin, X. Wang, F. Wang, Y. Shi, W. Hu, Y. Xu and X. Wang, Adv. Mater., 2020, 32, 1902039.

4 M. J. van Gemert, S. L. Jacques, H. J. Sterenborg and W. M. Star, IEEE Trans. Biomed. Eng., 1989, 36, 1146-1154.

5 C. Cheng, S. Li, A. Thomas, N. A. Kotov and R. Haag, Chem. Rev., 2017, 117, 1826-1914.

6 E. O. Polat, G. Mercier, I. Nikitskiy, E. Puma, T. Galan, S. Gupta, M. Montagut, J. J. Piqueras, M. Bouwens, T. Durduran, G. Konstantatos, S. Goossens and F. Koppens, Sci. Adv., 2019, 5, 7846.

7 W. Bai, T. Kuang, C. Chitrakar, R. Yang, S. Li, D. Zhu and L. Chang, Biosens. Bioelectron., 2018, 122, 189-204.

8 N. P. Shetti, A. Mishra, S. Basu, R. J. Mascarenhas, R. R. Kakarla and T. M. Aminabhavi, ACS Biomater. Sci. Eng., 2020, 6, 1823-1835.

9 X. Yu, S. Zhang, H. Zeng and Q. J. Wang, Nano Energy, 2016, 25, 34-41.

10 Y. Gong, P. Adhikari, Q. Liu, T. Wang, M. Gong, W. L. Chan, W. Y. Ching and J. Wu, ACS Appl. Mater. Interfaces, 2017, 9, 11016-11024. 
11 Z. Sun, Z. Liu, J. Li, G. A. Tai, S. P. Lau and F. Yan, Adv. Mater., 2012, 24, 5878-5883.

12 C. Wang, Y. Wang, L. Xu, D. Zhang, M. Liu, X. Li, H. Sun, Q. Lin and B. Yang, Small, 2012, 8, 3137-3142.

13 Y. Zhang, G. Hong, Y. Zhang, G. Chen, F. Li, H. Dai and Q. Wang, ACS Nano, 2012, 6, 3695-3702.

14 Y. Lei, L. Gu, X. Yang, Y. Lin and Z. Zheng, Adv. Mater. Interfaces, 2021, 8, 2002255.

15 H. Xu, B. W. Zeiger and K. S. Suslick, Chem. Soc. Rev., 2013, 42, 2555-2567.

16 I. Ka, V. Le Borgne, K. Fujisawa, T. Hayashi, Y. A. Kim, M. Endo, D. Ma and M. A. El Khakani, Mater. Today Energy, 2020, 16, 100378.

17 J. Lee, M. Kim, C. K. Hong and S. E. Shim, Meas. Sci. Technol., 2007, 18, 3707-3712.

18 Y. Zhang, Y. Liu, C. Li, X. Chen and Q. Wang, J. Phys. Chem. $C, 2014,118,4918-4923$.

19 G. Hwang, Y.-T. Shieh and K. Hwang, Adv. Funct. Mater., 2004, 14, 487-491.

20 Y. Ding, J. Zheng, X. Xia, T. Ren and J. Kan, LWT-Food Sci. Technol., 2016, 67, 206-213.

21 S. I. Sadovnikov and E. Yu Gerasimov, Nanoscale Adv., 2019, 1, 1581-1588.

22 A. I. Gusev and S. I. Sadovnikov, Thermochim. Acta, 2018, 660, $1-10$.

23 H. Doh, S. Hwang and S. Kim, Chem. Mater., 2016, 28, 81238127.

24 W. Jiang, Z. Wu, X. Yue, S. Yuan, H. Lu and B. Liang, $R S C$ Adv., 2015, 5, 24064-24071.

25 K. Cheng, X. Yang, X. Zhang, J. Chen, J. An, Y. Song, C. Li, Y. Xuan, R. Zhang, C. Yang, X. Song, Y. Zhao and B. Liu, Adv. Funct. Mater., 2018, 28, 1803118.

26 Y. Delgado-Beleño, M. Cortez-Valadez, C. E. Martinez-Nuñez, R. Britto Hurtado, R. A. B. Alvarez, O. Rocha-Rocha, H. Arizpe-Chávez, A. Perez-Rodríguez and M. Flores-Acosta, Chem. Phys., 2015, 463, 106-110.

27 S. I. Sadovnikov, E. G. Vovkotrub and A. A. Rempel, Dokl. Phys. Chem., 2018, 408, 81-84.
28 L. G. Bulusheva, A. V. Okotrub, A. G. Kurenya, H. Zhang, H. Zhang, X. Chen and H. Song, Carbon, 2011, 49, 40134023.

29 M. H. Kang, S. H. Kim, S. Jang, J. E. Lim, H. Chang, K. Kong, S. Myung and J. K. Park, RSC Adv., 2018, 8, 28447-28452.

30 I. Ka, V. Le Borgne, D. Ma and M. A. El Khakani, Adv. Mater., 2012, 24, 6289-6294.

31 D. Wang, J. K. Baral, H. Zhao, B. A. Gonfa, V. Truong, M. A. El Khakani, R. Izquierdo and D. Ma, Adv. Funct. Mater., 2011, 21, 4010-4018.

32 W. Feng, C. Qin, Y. Shen, Y. Li, W. Luo, H. An and Y. Feng, Sci. Rep., 2015, 4, 3777.

33 K. Akamatsu, S. Takei, M. Mizuhata, A. Kajinami, S. Deki, S. Takeoka, M. Fujii, S. Hayashi and K. Yamamoto, Thin Solid Films, 2000, 359, 55-60.

34 R. Zamiri, H. Abbastabar Ahangar, A. Zakaria, et al., Chem. Cent. J., 2015, 9, 28.

35 R. V. Kumar, O. Palchik, Y. Koltypin, Y. Diamant and A. Gedanken, Ultrason. Sonochem., 2002, 9, 65-70.

36 Y. Lei, H. Jia, W. He, Y. Zhang, L. Mi, H. Hou, G. Zhu and Z. Zheng, J. Am. Chem. Soc., 2012, 134, 17392-17395.

37 M. Shiraishi and M. Ata, Carbon, 2001, 39, 1913-1917.

38 P. Liu, Q. Sun, F. Zhu, K. Liu, K. Jiang, L. Liu, Q. Li and S. Fan, Nano Lett., 2008, 8, 647-651.

39 L. Gao, D. Dong, J. He, K. Qiao, F. Cao, M. Li, H. Liu, Y. Cheng, J. Tang and H. Song, Appl. Phys. Lett., 2012, 24, 6289-6294.

40 Y. Shen, J. Lifante, E. Ximendes, H. D. A. Santos, D. Ruiz, B. H. Juárez, I. Zabala Gutiérrez, V. Torres Vera, J. Rubio Retama, E. Martín Rodríguez, D. H. Ortgies, D. Jaque, A. Benayas and B. Del Rosal, Nanoscale, 2019, 11, 1925119264.

41 A. H. Poh, F. R. M. Adikan and M. Moghavvemi, Med. Biol. Eng. Comput., 2020, 58, 1159-1175.

42 J. F. Miethe, F. Lubkemann, N. C. Bigall and D. Dorfs, Front. Chem., 2019, 7, 1-11. 